\title{
1
}

\section{EL CONTROL DE EMPRESAS ESTATALES EN LA ENCRUCIJADA. LA COMISIÓN NACIONAL DE REGULACIÓN DEL TRANSPORTE Y LAS NUEVAS SOCIEDADES FERROVIARIAS EN ARGENTINA ${ }^{1}$}

\author{
Julián Bertranou $\cdot$ \\ Universidad Nacional de San Martin / \\ Universidad Nacional de Cuyo
}

\begin{abstract}
RESUMEN
Los entes denominados reguladores fueron creados en los años 90 en el marco de las privatizaciones y concesiones de servicios públicos, con el propósito de controlar las nuevas empresas operadoras privadas. En los últimos años, estos entes han debido ejercer este control sobre empresas que fueron estatizadas. Tal es el caso de la Comisión Nacional de Regulación del Transporte, que debe ahora fiscalizar el desempeño de operadores ferroviarios estatales. El ejercicio de esta función de control se ve dificultado en ese caso por situaciones de incertidumbre normativa y de resistencia por parte de las empresas estatales. Esta situación agrava la desorganización del sector ferroviario y afecta la calidad y la seguridad de los servicios. Un nuevo arreglo de coordinación y cooperación interorganizacional es imprescindible.
\end{abstract}

\section{PALABRAS CLAVE:}

Entes reguladores, Control, CNRT, Empresas estatales, Ferrocarriles.

\footnotetext{
(•)E-mail: jbertranou@hotmail.com; jbertran@unsam.edu.ar
}

\section{KEY WORDS:}

Regulatory Agencies, Control, CNRT, State Companies, Railways.

RECEPCIÓN: 24/06/20

ACEPTACIÓN FINAL: 27/08/20 
1 PLANTEAMIENTO DEL PROBLEMA DE LA FUNCIŌN DE CONTROL

Este artículo aborda la función de control ejercida por los denominados "entes reguladores" creados durante la década de los años 90, algunos de los cuales están llamados desde hace unos años, a ejercer la supervisión de empresas estatales (bajo distintos formatos jurídicos: sociedades del estado o sociedades anónimas de capital estatal), en vez (o no sólo) de empresas privadas. El caso que será analizado con algún detalle es el de la Comisión Nacional de Regulación del Transporte (CNRT).

¿Es enteramente novedosa esta nueva institucionalidad de entes reguladores públicos y de organismos operadores o prestadores también públicos? En cierta medida, esto representa una novedad, pero el control ha sido y es una función ejercida frecuentemente por organismos públicos sobre otros organismos del mismo estatus. La cuestión es la de distinguir qué tipo de control es el que se está ejerciendo, y qué tipo de relación es la que se construye o debe construirse entre estos organismos estatales.

La actividad de control es intrínseca al Estado y a la Administración Pública. Sobre el accionar estatal, generalmente llevado a cabo por el órgano ejecutivo del Estado, se ciernen distintos controles, entre ellos, algunos de tipo político, como los parlamentarios o judiciales. También se cierne sobre ellos el control 
que sobre los actos públicos ejercen los llamados Organismos de Control, como los Tribunales de Cuentas o las Auditorías Generales, los cuales se abocan a la legalidad de los actos y al manejo del patrimonio público. Adicionalmente a estos controles políticos o institucionales extra Poder Ejecutivo, se despliega una gran variedad de controles que ejercen organismos ejecutivos, con el objeto de garantizar los resultados sustantivos en la gestión pública, o al menos, el cumplimiento de procedimientos básicos.

El análisis de los mecanismos de control ha tenido un importante impulso en los últimos 30 años en la región de América Latina y el Caribe. Bajo distintos enfoques y en un contexto de consolidación de los regímenes democráticos, se desplegaron distintos conceptos como el de accountability ${ }^{2}$, que permitieron analizar el estado actual de los mecanismos de control en la región, así como proponer innovaciones institucionales que perfeccionaran su desempeño. Trabajos como los de O'Donnell $(1996,1998)$ sobre accountability horizontal, del CLAD (2001) sobre modalidades de responsabilización (que incluyen el control social y el control por competencia administrada), y el de Oszlak (2003) diferenciando responsabilidad, de responsabilización y respondibilidad, son algunos de los aportes más significativos.

Al interior de las disciplinas administrativas y su foco en el ejercicio de la función administrativa propiamente tal, la función de control ha sido incluida como un componente central. ${ }^{3}$ Las alusiones hasta aquí descubren algunas variedades en la caracterización de la función de control, que fueron ya advertidas por Oszlak (2003). Por un lado, dentro de la perspectiva de la responsabilización, el foco está puesto en la rendición de cuentas, en la obligación de las organizaciones públicas y sus responsables de dar cuenta de sus actividades y resultados. Por otro lado, y no de manera contradictoria con el punto anterior, encontramos el control como una función que deben cumplir unidades dentro de organizaciones $u$ organizaciones independientes, para garantizar que se haya materializado la coordinación necesaria para el cumplimiento de los propósitos de una organización pública. Este último foco se relaciona con la propia definición que del control planteó Fayol (1971).

Este es el foco prioritario de este trabajo, sin que se olvide la dimensión de rendición de cuentas que todo proceso de control conlleva. El extraordinario volumen colectivo editado por Kaufmann, Majone y Ostrom (1985), relaciona las dimensiones de gestión fundamentales de dirección, control y evaluación con el requerimiento central de coordinación. En otras palabras, «el problema de la coordinación entre diversos actores semiautonómos debe ser analizado en relación con las tres dimensiones de dirección (guidance), control y eva- 
luación" (Wirth, 1985, en el mencionado volumen). Para Wirth, "el control es una función de información y motivación para una conformidad inteligente con un sistema de acciones interrelacionadas, guiadas por estándares más o menos aceptados en general, y establecidos para el desempeño de los actores involucrados" (p. 595). La importancia de los estándares es gravitante, y será este un aspecto importante en la evaluación del desempeño de la propia CNRT en los próximos apartados. Los estándares son de procedimientos operativos, pero también de productos y resultados a lograr.

En términos generales, el control en la Administración Pública implica:

- El monitoreo y la apreciación de decisiones, procedimientos y productos administrativos.

- Las intervenciones preventivas o correctivas con el objeto de reforzar el cumplimiento de las reglas y evitar o rectificar desviaciones intolerables de actividades administrativas o sus resultados (no intencionados).

- El ajuste o modificación de estos estándares, fines, o reglas en el contexto de cambios o potenciales cambios en la situación problema (Wirth, 1985, p. 600).

Las formas en que esta función se ha ejercido en la Administración Pública son muy diversas, dependiendo del tipo de actividad o servicio a controlar y de la asignación de la responsabilidad en alguna organización o persona responsable. Una primera clasificación institucional que involucra el control que organismos estatales ejercen sobre otros organismos de igual procedencia, excluyendo las modalidades judiciales o políticas, es la siguiente:

- Control interno - Auditoría interna (en el caso del Estado Nacional, liderado por la Sindicatura General de la Nación - SIGEN). ${ }^{4}$

- Control externo (a cargo en el ámbito nacional de la Auditoría General de la Nación - AGN).

- Control regulatorio, sustantivo y operativo, de procedimientos, productos y resultados (por ejemplo: el Banco Central y la superintendencia del sistema bancario público y privado; la CNRT y el control de operadores privados y también públicos, entre otros muchos ejemplos).

Si bien son de larga data los ejemplos de esta última modalidad de control sustantivo, un incremento de los casos se debió a la creación de agencias llamadas reguladoras de los servicios públicos en la década de los años 90 , las cuales debieron incorporar la supervisión de empresas u organismos luego 
estatizados durante los años 2000 y 2010, tanto en el nivel nacional como provincial. Hasta el momento, es escasa la atención que este cambio institucional ha producido en el ámbito académico.

Este trabajo tiene como propósito general analizar el ejercicio de las funciones de control sustantivo de los entes públicos de fiscalización en relación con operadores también públicos, tomando como caso especial la relación entre la Comisión Nacional de Regulación del Transporte (CNRT) y los operadores y administradores públicos del servicio ferroviario creados a partir de 2008: la Operadora Ferroviaria Sociedad del Estado (SOF), la Administradora de Infraestructuras Ferroviarias Sociedad del Estado (ADIF) y la empresa Belgrano Cargas y Logística Sociedad Anónima (BCyL). ${ }^{5}$

Por distintas razones, las funciones de fiscalización y control que debe ejercer la CNRT en relación con operadores u organismos estatales adolecen, en muchos casos, de grados de confusión e incertidumbre o son, en otros casos, impracticables o fuertemente impugnadas. Esto está relacionado principalmente con el bajo grado de explicitación de los estándares de fiscalización, las imprecisiones del ordenamiento legal y la autorreferencia institucional, que impiden ver el servicio público como una contribución institucional de conjunto.

El trabajo se organiza de la siguiente manera: en el apartado siguiente se introducirá el fenómeno de las agencias y en especial, de las agencias reguladoras creadas en los años 90; en el tercer apartado se describirán las características institucionales de la CNRT y en el cuarto, se describirán las particularidades, tensiones y limitaciones de la fiscalización de organismos públicos; finalmente, se cerrará con un balance general de este proceso y con algunas recomendaciones para el rediseño institucional del sector.

\section{LAS AGENCIAS ESPECIALIZADAS Y EL CONTROL}

\subsection{AGENCIAS ESPECIALIZADAS Y DESCENTRALIZADAS ${ }^{6}$}

Entre las orientaciones de reforma administrativa que surgieron bajo la inspiración intelectual y política del movimiento conocido como Nueva Gestión Pública (NPM por su sigla en inglés) en los países centrales a partir de fines de los años 80 , se encuentra la creación de agencias públicas temáticamente especializadas y autónomas de las autoridades políticas y los ministerios centralizados. Esta tendencia ha sido analizada de manera general y a través de las distintas trayectorias experimentadas por los países en trabajos como el 
de Pollitt y Bouckaert (2004), y responde a un momento determinado en los sucesivos ciclos de desburocratización y re-burocratización que se han suscitado por las administraciones públicas en el mundo (Olsen, 2008).

La creación de agencias autónomas ha sido considerada como un medio para separar parcialmente la gestión de las políticas públicas de la dinámica política, para que esta gestión se desarrolle de manera más profesional y especializada (Peters, 2011). La conjunción de una mayor autonomía respecto de la actividad política y de una mayor estabilidad programática, por un lado, y de una mayor especialización en el ejercicio de sus funciones, por el otro, ha sido considerada como un medio para poder acrecentar los mecanismos de rendición de cuentas del sector público, permitiendo una mejor medición de los costos y de los resultados de la gestión pública. Las ventajas potenciales de estas agencias se extienden también al ámbito de las flexibilidades administrativas, financieras y de manejo de personas que se derivan de un marco institucional autónomo, flexibilidades que han constituido una de las orientaciones centrales de las reformas inspiradas en la NPM (Osborne y Gaebler, 1994).

Si bien las agencias han existido desde hace mucho tiempo, a partir de fines de los años 80 hubo un resurgimiento muy significativo. El énfasis puesto por el NPM en la delegación, la desagregación y la tercerización al sector privado, llevó a que funciones tradicionalmente cumplidas por organizaciones burocráticas centralizadas se transfirieran a una gama de organizaciones cuasi autónomas y monofuncionales. El proceso de creación de estas agencias estuvo caracterizado por distintos estilos administrativos, advirtiéndose que estos estilos están estrechamente vinculados a las características de los sectores de política pública (Van Thiel, 2006). Cada área de política pública tiene una serie de particularidades derivadas de su historia, de la naturaleza de los bienes y servicios que se proveen y de los actores que allí intervienen, lo cual da pie a diferentes estilos de creación de agencias autónomas. Los tipos de agencias creadas también son el resultado de tradiciones y de complejos procesos históricos y culturales, más que de explicaciones de coyuntura política (Yesilkagit y Christensen, 2009).

La creación de agencias autónomas en los países centrales despertó con el tiempo una serie de críticas. Por un lado, el proceso de creación de estas "single-purpose organizations" (organizaciones de un solo propósito) produjo lo que algunos autores denominan la "siloización" o «pilarización" del sector público (Christensen y Laegreid, 2007, p.541), idea que significa que la miríada de organizaciones especializadas debió producir "demasiada segmentación, autoridades centradas en sí mismas, y falta de cooperación y coordinación, y 
por tanto, se entorpeció la efectividad y eficiencia" (p. 542). Por otro lado, el desarrollo de algunas de estas agencias ha planteado serios desafíos al principio de rendición de cuentas democrático o accountability (Christensen y Laegreid, 2007; Peters, 2011). Adicionalmente, se han suscitado otros problemas de rendición de cuentas atribuidas a los líderes políticos. Éstos siguen siendo responsables ante la ciudadanía por la conducción de los asuntos públicos, pero simultáneamente, han visto perder liderazgo político y control sobre ciertas organizaciones autónomas.

La creación de agencias autónomas también formó parte del universo de estrategias de reforma del estado implementadas a partir de los años 90 en América Latina. Al igual que en los países centrales, estas agencias, de muy diversa factura, también existen desde mucho tiempo atrás en la región, pero su cantidad se vio acrecentada en los últimos 20 años. Antecedentes tempranos de esta nueva tendencia pueden encontrarse en los Fondos de Inversión Social de la década de los años 80 (Franco, 1996). La variedad de agencias es muy grande e incluye empresas privatizadas, entes reguladores (Azpiazu y otros, 2008; Serafinoff, 2011; Murillo, 2009; Guerra, 2012), agencias especializadas profesionalizadas, agencias de recaudación impositiva (Depetris, 2011), agencias científico-tecnológicas, agencias de control e incluso, agencias mixtas público-privadas (Bertranou, 2011; Bresser Pereira, 1999).

La creación de agencias obedeció tanto a un clima de época en materia de reforma del estado, como a factores endógenos, que definieron formatos y trayectorias en función de requerimientos propios ${ }^{7}$.

En la creación de estas agencias entraron a tallar diferentes motivaciones:

a) La necesidad de desprenderse de unidades gubernamentales en un proceso de reducción del tamaño del estado.

b) Las exigencias de organismos multilaterales de crédito en los procesos de reforma del estado y concesionamiento de los servicios públicos.

c) La necesidad de agilizar y hacer más eficiente la gestión pública, sustrayendo algunas actividades "... de la compleja maraña burocrática en la que se ve involucrada la mayor parte de la administración central» (Oszlak, 2001, p. 9). ${ }^{8}$

d) La pretensión de fortalecer la especialización de la intervención pública y mejorar su profesionalidad, capacidad y desempeño.

e) La necesidad de incorporar a distintos intereses sectoriales y regionales en la gestión de asuntos públicos, y entre ellos, al sector privado.

f) La posibilidad de administrar con mayor autonomía recursos de asignación específica. 
g) La necesidad de mostrar a la opinión pública que un asunto está en la agenda de gobierno.

Como advierte Oszlak, «la fórmula automaticidad de ingresos + discrecionalidad en su aplicación, resultó históricamente demasiado atractiva como para optar por otro arreglo institucional» (2001, p. 9). En los hechos, medidas legales y reglamentarias emitidas por la instancia central para controlar el uso de los fondos, así como la escasa autonomía política de los funcionarios y funcionarias de estas agencias, ha limitado los alcances de la autonomía institucional y funcional. La mayoría de estas agencias son «híbridos institucionales» (Oszlak, 2001).

Los casos de agencias creadas en la Argentina (y posiblemente en la Región), no responden necesariamente a los motivos que centralmente caracterizaron el proceso de agencización en los países centrales, ya que no tuvo como condimento principal, el logro de autonomía de las autoridades políticas. En el caso argentino, si bien este aspecto estuvo presente en pocos casos, los rasgos más salientes están vinculados a la idea de autonomía de los procesos administrativos centrales y a la de la búsqueda de cierta densidad profesional, esto más allá de su efectivización posterior.

\subsection{AGENCIAS REGULADORAS EN ARGENTINA A PARTIR DE LOS AÑOS 90}

La creación de agencias especializadas toma un impulso a comienzos de la década de los años 90, en el marco de la reestructuración de las funciones del Estado Nacional comenzada con la sanción en 1989 de las leyes 23696 y 23697 de Reforma del Estado y de Emergencia Económica, respectivamente.

El traspaso de las funciones de operación de los servicios públicos esenciales al sector privado, bajo la forma de concesiones integrales o de privatizaciones, requirió de la creación de organismos comúnmente llamados "reguladores", legalmente independientes, con el objeto de ejercer el control por parte del Estado de las operaciones transferidas, abordar las "fallas de mercado" y las asimetrías de información y fijar reglas para el desarrollo de las actividades.

Pueden mencionarse los casos iniciales de la Comisión Nacional de Telecomunicaciones (CNT, Decreto 1185/90), el Ente Nacional Regulador de la Electricidad (ENRE, Ley 24065), el Ente Nacional Regulador del Gas (ENARGAS, Ley 24076) y el Ente Tripartito de Obras y Servicios Sanitarios (ETOSS, Decreto 992/92). La emergencia de estas instituciones fue acompañada por una serie de debates sobre aspectos relevantes a tener en cuenta: las funciones que las mismas podrían desarrollar y su grado de autonomía. 
Con respecto al primer punto, el tema central tenía que ver con el ejercicio de funciones de regulación técnica y económica de los servicios públicos. Estos últimos, por las razones expuestas por especialistas (Nahón y Bonfiglio, 2007; Rocca, 2013) $)^{9}$, requieren de explícitas regulaciones ${ }^{10}$. Previo a las privatizaciones, la regulación estaba a cargo de la empresa pública prestadora (monopólica) o bien a cargo de los Ministerios de línea respectivos, pero era frecuente encontrar vacíos de regulación propios de considerar a estas empresas y los servicios prestados por ellas como inexorablemente orientados al bien común (y a los usuarios, consecuentemente). La llamada «noción moderna de regulación", es la ejercida por organismos autónomos frente a empresas privadas luego de procesos de privatización o concesionamiento (Naón y Bonfiglio, 2007). Pero esta nueva dimensión de la regulación no sólo debería contemplar aspectos más clásicos como el de las tarifas, aspectos técnicos o la defensa de la competencia, sino cuestiones como el acceso y la cobertura (universal), la defensa de los derechos de los usuarios ${ }^{11}$ y la sustentabilidad de los servicios en el mediano y largo plazo.

Las primeras agencias incluyeron una porción de estas funciones regulatorias, como veremos con el caso de los organismos antecesores de la CNRT, pero otra generación de agencias a partir de mediados de los años 90, no las incluyeron. En términos más generales, la función de regulación permaneció en la esfera del Poder Ejecutivo, salvo en aspectos más reglamentarios y de operacionalización de normas técnicas, que sí fueron alojadas en los nuevos entes. Las funciones principales de estos entes fueron entonces de fiscalización y control ${ }^{12}$, de resolución de conflictos (el caso de la CNRT es uno de ellos), e incluso de gestión (aspectos que mencionaremos más adelante.

Con respecto al segundo punto, el de la independencia o autonomía del organismo, ésta debe presentarse según Cicero (1996, citado en Papazián, 2000) en dos facetas: «(a) Independencia frente al poder político: No es legítimo sujetar a los directorios de los entes a instrucciones o directivas respecto de la forma en que deben ejercer sus funciones. Si se quiere preservar su carácter de organismos administrativos altamente especializados, debe evitarse caer en la tentación de querer dirigirlos a través de medidas que van más allá de la facultad del superior jerárquico, de coordinar sus actividades con el resto del aparato estatal: ello puede dar lugar a que se desdibujen sus funciones y se diluyan las atribuciones con las cuales han sido creados; y (b) Independencia frente a los controlados: ¿Cómo se logra que los entes no sucumban al poder económico de los controlados ? 1) Seleccionando personal idóneo y honesto; y 2) Promoviendo mecanismos de participación comunitaria». Esto es lo que se 
denomina el peligro de la cooptación bifronte (Nahón y Bonfiglio, 2007; Rocca, 2013). Para los autores, un antídoto para estos intentos de cooptación serían la autarquía financiera y la autonomía funcional. Como se menciona en el apartado anterior, y más allá de las diferencias entre los entes creados por ley respecto de los creados por decreto, la injerencia del Poder Ejecutivo en la Argentina es muy significativa, en especial, en lo referente al nombramiento y remoción de los cuadros gerenciales de los organismos. Independientemente de las disposiciones legales, la superintendencia político-partidaria de estos entes licúa fácilmente su independencia. De manera complementaria, la consagración del recurso administrativo jerárquico o "de alzada» limita en gran medida la autonomía para aplicar sanciones, aspectos que luego se mencionará para el caso de la CNRT.

La contemporaneidad de la reestructuración del Estado en la Argentina y el despliegue a nivel mundial de una nueva forma de organizar las funciones dentro del Estado a través de "organizaciones de propósito único" (Laegreid y otros, 2008) tal como fue comentado en el subapartado anterior ${ }^{13}$, tuvo como producto la creación de estos "entes reguladores". El escenario institucional del Estado se hizo más complejo y diversificado.

A partir de 2004 con la empresa Correo Oficial de la República Argentina S.A. (Decreto $N^{\circ} 721 / 04$ ), se inicia un proceso paulatino y parcial de estatizaciones que abarca determinados servicios públicos y empresas energéticas. Se plantea entonces la pregunta sobre la propia existencia de estos entes reguladores, en especial en ámbitos en donde los operadores son sólo públicos. La respuesta general fue la de mantenerlos, pero la delimitación de sus roles en relación con las empresas prestadoras (públicas o privadas) y el propio Poder Ejecutivo, no fue tratado en todos los casos con la importancia y la efectividad requerida (Nahón y Bonfiglio, 2007). Está claro que no hubo un retorno a la experiencia de las empresas públicas multipropósito (Bertranou, 2019), pero tampoco hubo en todos los casos, una práctica institucional que estableciera un ordenamiento adecuado de funciones a ser desempeñadas por todos los actores del sector. Estos puntos generales nos permitirán abordar el caso de la CNRT.

\section{LA COMISIÓN NACIONAL DE REGULACIÓN DEL TRANSPORTE Y LA FISCALIZACIÓN DE CONCESIONARIOS PRIVADOS}

A partir del año 1990 (aunque hubo antecedentes), comienza el proceso de restructuración de los servicios ferroviarios de pasajeros y de cargas pertenecientes a la empresa estatal Ferrocarriles Argentinos (FA). Los distintos com- 
ponentes del servicio (pasajeros metropolitanos, pasajeros de larga distancia y cargas) fueron sometidos a procesos de transformación que buscaron desligar al Estado Nacional de la operación directa de los mismos. Con la creación de FEMESA ${ }^{14}$ se escinden los servicios metropolitanos de la red general y se encara el proceso de concesionamiento integral que desembocará entre los años 1994 y 1995 en la adjudicación de los 7 ramales existentes a cuatro empresas privadas (Pérez, 2015; Kohon, 2019). Los servicios de pasajeros de larga distancia fueron los más afectados: aquellos servicios que no pudieran ser absorbidos por las provincias, serían directamente dados de baja. La red de cargas fue dividida en 6 zonas de explotación y dada en concesión por 30 años a cinco empresas. La red del Ferrocarril Belgrano no pudo ser adjudicada y pasó a ser gestionada por diversas empresas y arreglos de gestión bajo una fuerte tutela estatal (Kohon, 2019).

Si bien la CNRT fue creada como agencia de fiscalización de estos sistemas en noviembre de 1996 (Decreto 1388/96), es decir, con las nuevas concesiones en marcha, hubo previamente organismos que ejercieron el control y que incluso, participaron del proceso de adjudicación, contrariamente a lo que se afirma (Oszlak y otras, 2000). Durante el período que va desde fines de 1992 y mediados de 1994 se crearon cuatro organismos específicos relacionados con el nuevo esquema de gestión ferroviaria (a los que se sumará también la Comisión Nacional de Transporte Automotor - CoNTA, en lo que será luego la formación de la CNRT): i) la Comisión Nacional de Regulación Ferroviaria (CNRF) para resolver controversias entre los concesionarios de servicios ferroviarios de cargas, de pasajeros interurbanos y de pasajeros metropolitanos (entre sí, con los dadores de carga o con el Estado), lograr que el sistema ferroviario sea competitivo con relación a otros modos y prevenir conductas monopólicas por parte de los operadores, ii) la Comisión Nacional de Transporte Ferroviario (CNTF), creada con la finalidad de fiscalizar las concesiones de transporte ferroviario interurbano de pasajeros y de carga, y entender en la regulación relativa a la seguridad del transporte por vía férrea en todo el país, iii) la Unidad de Coordinación del Programa de Reestructuración Ferroviaria (UCPRF), creada a los efectos de asegurar la fiscalización y el control de las concesiones para la explotación de los servicios de transporte ferroviario - de superficie y subterráneo - del Área Metropolitana, y iv) el Tribunal Arbitral del Transporte Ferroviario, con la misión específica de resolver controversias relacionadas con los contratos de concesión o de transporte que se produzcan entre las empresas de transporte ferroviario, o entre éstas y los usuarios o el Estado Nacional (reemplazando las funciones de la CNRF). 
Los organismos mencionados pertenecen a una primera generación de los llamados entes reguladores, caracterizada por una mayor especialización funcional (modal), mayor descentralización administrativa y la inclusión de algunas potestades propiamente de regulación de los servicios y de resolución de conflictos, además de las de fiscalización y control (Papazian, 2000). Con la CNRT se diseña otro tipo de organismo de la mano de las facultades para la reorganización del Estado que se desprenden de la Ley 24.629/96, asociada a lo que luego fue conocido como segunda reforma del Estado. La CNRT fusiona las entidades anteriormente mencionadas, además de la CoNTA, para convertirse en la agencia nacional descentralizada responsable de la fiscalización y control del transporte terrestre de jurisdicción nacional, sin potestades en materia de regulación y resolución de conflictos, aunque con la posibilidad de emitir algunas normas técnicas específicas para el desenvolvimiento de los servicios ${ }^{15}$. Desde un principio sus competencias incluyeron los siguientes sectores: a) el transporte automotor de pasajeros (urbano AMBA, líneas 1 a 199, urbano interjurisdiccional del interior del país (Cipolletti-Neuquén, por ejemplo) e interjurisdiccional de media y larga distancia); b) trenes de pasajeros de la región metropolitana; c) trenes de pasajeros de larga distancia; d) transporte automotor y ferroviario de cargas; e) estación terminal de ómnibus de Retiro.

El Decreto 1388/96 establece la integración de la CNRT, sus funciones y aprueba la estructura organizativa en su primer nivel de apertura. Dicho Decreto define como objetivos institucionales:

- Instrumentar los mecanismos necesarios para garantizar la fiscalización y el control ${ }^{16}$ de la operación del sistema de transporte automotor y ferroviario, de pasajeros y carga de Jurisdicción Nacional, con el objetivo de garantizar la adecuada protección de los derechos de los usuarios y promover la competitividad de los mercados.

- Ejercer el poder de policía en materia de transporte de su competencia, controlando el cumplimiento efectivo de las leyes, decretos y reglamentaciones vigentes, así como la ejecución de los contratos de concesión; y fiscalizar la actividad realizada por los operadores de transporte.

- Asistir a la autoridad de aplicación en todos aquellos aspectos relativos a su competencia.

Su estructura interna, compuesta inicialmente por siete gerencias, refleja la yuxtaposición de dos modos terrestres, automotor y ferroviario, con culturas y prácticas claramente distintas. Esta fragmentación se expresa también al interior del modo ferroviario, donde la fiscalización se distribuye en dos gerencias muy 
diferenciadas, una dirigida a la calidad del servicio y la otra a la seguridad. ${ }^{17}$ Estas gerencias aplican normas y tienen prácticas de fiscalización distintas.

El estatuto de la CNRT fue actualizado en 2015 (Decreto 1661), el cual se dio una vez concluida la intervención administrativa que databa de 2001. El nuevo estatuto reafirma en su artículo $3^{\circ}$ los siguientes objetivos para el organismo: a) proteger los derechos de los usuarios, b) promover la competitividad en los mercados de las modalidades del transporte aquí comprendidas y $\mathrm{c}$ ) promover mayor seguridad, calidad y eficiencia en el servicio, mejor operación, confiabilidad, igualdad y uso generalizado del sistema de transporte automotor $y$ ferroviario, de pasajeros y de carga, asegurando un adecuado desenvolvimiento en todas sus modalidades.

Desde el punto de vista de este artículo, es importante analizar las nuevas disposiciones en materia de fiscalización ferroviaria. Estas funciones se desprenden de los artículos $8^{\circ}$ y $9^{\circ}$ del Decreto 1661 , y sus respectivos incisos. ${ }^{18}$ En el artículo $10^{\circ}$ se establece que en función de lo mencionado, la CNRT podrá: a) requerir información a las empresas y operadores ferroviarios y efectuará inspecciones «in situ» para determinar el grado de cumplimiento dado por ellos a las normas relativas a la seguridad en la operación, en los materiales de vía, material rodante, estructuras y equipamientos de seguridad incorporados y al mantenimiento de los mismos, así como aquellas cuestiones vinculadas a la calidad del senvicio y conservación de los bienes; b) ordenar a las empresas y operadores ferroviarios las acciones que deberán cumplir, con vistas al acatamiento de las normas sobre seguridad y calidad ferroviaria, cuando se comprueben deficiencias u omisiones en su aplicación; c) promover la subsanación de las falencias constatadas a raíz de las inspecciones realizadas, emitiendo, cuando corresponda, directivas para su corrección y saneamiento; d) imponer las sanciones de llamados de atención, apercibimiento y multas a todo operador ferroviario privado o concesionario bajo su jurisdicción; e) imponer las sanciones de llamado de atención y apercibimiento a todo operador ferroviario estatal bajo su jurisdicción que no cumpla con las disposiciones relativas a la seguridad o calidad; entre otras competencias (énfasis propio).

En lo que se refiere al conjunto de operadores bajo la fiscalización de la CNRT, la situación fue cambiando con el correr de los años desde 1996. Con respecto a los concesionarios metropolitanos, en 2004 y 2007 se rescindieron los contratos de concesión de las líneas San Martín y Belgrano Sur y Roca, respectivamente, todas bajo la responsabilidad del concesionario Transportes Metropolitanos SA (Pérez, 2012, 2015). Estas rescisiones obligaron al Estado, sin un "plan B" con operadores propios, a transferir la gestión de los servicios 
a los tres concesionarios remanentes (los actuales concesionarios Metrovías SA y Ferrovías SA, además de TBA-Trenes de Buenos Aires SA). Estos concesionarios gestionaron conjuntamente las líneas rescindidas bajo la forma una empresa denominada UGOFE SA (Unidad de Gestión Operativa Ferroviaria de Emergencia, Res. ST 408/04).

El posterior colapso de TBA luego del siniestro de la Estación Once en 2012, llevó al Estado Nacional a rescindirle las dos concesiones a su cargo (líneas Mitre y Sarmiento) y a asignar la operación de las líneas a una nueva entidad de emergencia (UGOMS SA) integrada por los concesionarios remanentes. Hasta 2013 (Res. MlyT 511/1312), ni UGOFE y UGOMS tenían aprobado un régimen de penalidades por la gestión de estas cinco líneas rescindidas, y los contratos originales de concesión ya no estaban vigentes para estos casos. La CNRT carecía de parámetros para la fiscalización de la calidad de los servicios.

Los problemas de la gestión compartida de estas líneas a través de estas "unidades de emergencia», impulsó al Estado en 2014 a asignar a la gestión unilateral dos líneas a cada una las concesionarias remanentes, bajo nuevos acuerdos de operación (Res. MlyT 41/2014); con la excepción de la línea Sarmiento que comenzó a ser operada por la SOF a fines de 2013 (Res. MlyT 1244/2013), en un primer hito de estatización de la operación de los servicios.

El conjunto de las líneas que no estaban bajo concesión (es decir, todas menos las líneas Urquiza y Belgrano Norte) fueron nacionalizadas en 2015 (Res. MlyT 171/15) y quedaron bajo la operación de SOF. Con la asunción de la gestión de los servicios por parte de la SOF, fue necesario establecer un nuevo marco de normas para la fiscalización, el cual se puso en marcha recién en 2016, tres años después del inicio de la primera operación en el FC Sarmiento.

Los datos de fiscalización de las empresas concesionarias metropolitanas privadas, tanto en cantidad como en monto de las multas, puede verse en los Gráficos 1 y 2 . Algunos datos importantes que surgen de estas cifras y de otros elementos de juicio:

- La cantidad de multas se mantiene baja durante los primeros años de las concesiones, pero comienza a incrementarse a partir de 1998, encontrando un máximo en la crisis de 2002.

- La cantidad de multas y sobre todo, su importe, es el reflejo del deterioro creciente de algunos de servicios y se relaciona con los años de las rescisiones de los contratos. En el año 2004 los datos de Metropolitano, en especial en el ramal San Martín, revelan un estado muy deficitario del servicio. El contrato queda rescindido en 2004, y los ramales Belgrano Sur y Roca siguen con deficiencias hasta la rescisión de los contratos en 2007. 
- El desempeño de TBA tiene altibajos, pero se deteriora en especial desde el 2006, con multas abultadas, que culminan con los pésimos desempeños en los años previos al accidente de Once.

- La cantidad y el volumen de las multas de los concesionarios remanentes es muy significativa, visto en promedio, y considerando que son dos ramales chicos (debe recordarse que desde 2013, la CNRT no fiscaliza el Subterráneo bajo concesión a Metrovías, debido al traspaso de este segmento a la Ciudad de Buenos Aires).

- No hay datos de multas a UGOFE y sólo 2 multas a la UGOMS. Cabe recordar que los criterios de fiscalización de las UGOs fueron aprobados recién en 2013.

- Hubo una amplia actividad de fiscalización cuando se establecieron los contratos de gerenciamiento de la resolución 41/14 en favor de Metrovías y de Ferrovías, bajo la denominación empresarial Corredores Ferroviarios SA y Argentren SA, respectivamente.

- La actividad fiscalizadora de la CNRT anticipa las crisis ferroviarias, más allá de que sus intervenciones no tengan la continuidad sancionatoria necesaria.

\section{Gráfico 1.}

Montos de penalidades a concesionarias metropolitanas 1994-2019 (en pesos corrientes)

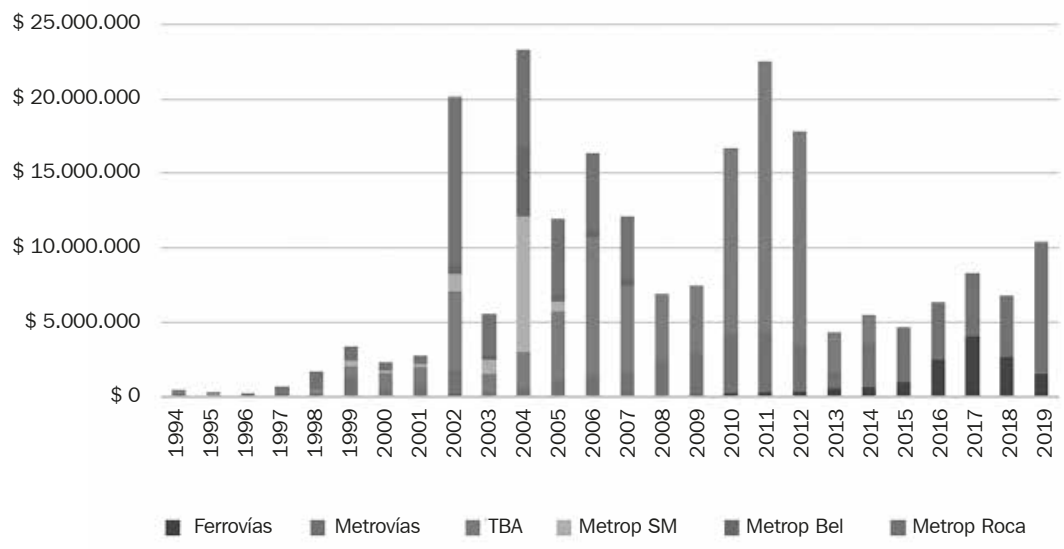

Fuente: elaboración propia en base a datos de CNRT. 


\section{Gráfico 2.}

Cantidad de penalidades a concesionarias metropolitanas 1994-2019

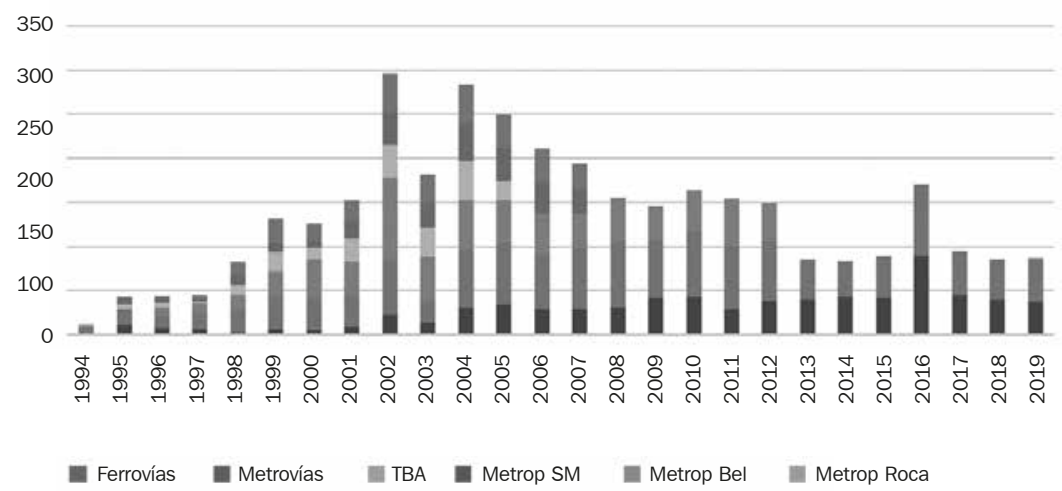

Fuente: elaboración propia en base a datos de CNRT.

En materia de cargas, el entramado de operadores/concesionarios también sufrió cambios. Por un lado, el derrotero del ramal Belgrano incluyó la creación de una sociedad anónima con capital estatal, la creación de una empresa con capital mayoritario de la Unión Ferroviaria para la gestión del senvicio, el traspaso de las funciones a una sociedad de emergencia integrada por empresas y sindicatos (SOESA), la intervención por parte del estado, y la gestión por parte de una nueva empresa con capital estatal en 2013 (Belgrano Cargas y Logística SA, Dec. 566/2013). Por otro lado, los ramales bajo administración de la empresa brasileña ALL (San Martín y Urquiza) sufrieron la rescisión del contrato de concesión en 2013, y pasaron a ser gestionados por la empresa estatal.

De forma resumida, con los cambios en la matriz de operadores, se produjeron paulatinamente cambios en el marco de las normas que establecen los criterios de fiscalización de la CNRT. Para los concesionarios privados originales se mantuvieron vigentes las normas de los contratos de concesión y de sus adendas, además de la Ley General de Ferrocarriles 2.873 y el Reglamento General de Ferrocarriles, en todo lo referido a lo que hemos denominado de manera más sintética, calidad y seguridad. Con los dispositivos de emergencia (UGOFE y UGOMS), los acuerdos de operación y las estatizaciones metropolitanas, se incorporaron de manera tardía nuevos criterios de fiscalización en materia de calidad, manteniéndose los mismos criterios en seguridad ${ }^{19}$. 
Una cuestión importante a destacar en esta caracterización de la CNRT, es que la fiscalización y el control en el ámbito ferroviario difiere de lo que acontece en el ámbito automotor, aun en el mismo marco de competencias del organismo. Los procedimientos sancionatorios en el caso ferroviario y a diferencia del caso automotor, carecen de ejecutividad. Un reciente documento interno de la CNRT manifiesta lo siguiente:

Por el contrario, en el ámbito del transporte ferroviario nacional y en el marco de los contratos de concesión aún vigentes, a través de los cuales se presta el servicio en el área metropolitana de la provincia de Buenos Aires, el cobro de multas por incumplimientos contractuales se persigue en un proceso de conocimiento - con mayor apertura de prueba y debate - que también tramitará ante el fuero contencioso administrativo federal...... En consecuencia, en este caso, la ejecutoriedad del acto no faculta a la Administración al cobro de la multa por sí misma, tampoco hay ley que lo dote de ejecutividad, debiendo acudir por lo tanto, a la jurisdicción ( es decir al poder judicial) para el cobro compulsivo de la multa en un proceso común, lo que en la práctica genera que a diferencia de la ejecución de sanciones en materia automotor, el cobro de multas aplicadas en el marco de incumplimientos a los contratos de concesión ferroviarios, genere mayores plazos, que en el caso del transporte automotor. ${ }^{20}$

Esta cualidad le ha restado poder a la CNRT en relación con los operadores de transporte ferroviario, dada la dificultad para hacer valer efectivamente sus competencias fiscalizadoras.

\section{LA CNRT Y EL NUEVO ESCENARIO CON OPERADORES Y ORGANISMOS ESTATALES}

4. 1 LOS CAMBIOS INSTITUCIONALES PRINCIPALES

La reaparición de operadores $u$ organismos estatales ferroviarios comienza a producirse en 2008 con la sanción de la Ley 26.352 de Reordenamiento Ferroviario. La Ley creó dos Sociedades del Estado: la Administradora de Infraestructuras Ferroviarias (ADIF) y la Operadora Ferroviaria (SOF); la primera, encargada de la administración de la infraestructura ferroviaria actual y futura, su mantenimiento y la gestión de los sistemas de control de circulación de trenes; la segunda, a cargo de la prestación de los servicios de transporte fe- 
rroviario tanto de cargas como de pasajeros, en todas sus formas, que le sean asignados, incluyendo el mantenimiento del material rodante. Este esquema replica el modelo europeo de separación vertical entre la infraestructura y la operación (Barbero y Bertranou, 2014).

Las razones de esta innovación institucional fueron múltiples, aunque convergentes. Ante el creciente descontento con los servicios metropolitanos, y en especial con los prestados por las empresas Transportes Metropolitanos y TBA (Pérez y Rebón, 2017), que desembocó en las rescisiones de 2004 y 2007 , se reactivó una pretensión nacionalista, latente en el ámbito ferroviario, que canalizó en una primera instancia el presidente Néstor Kirchner, y cuyo objetivo planteado fue el de estatizar los servicios, pero que luego derivó en la inusual y poco estudiada propuesta de separación vertical de la gestión (Barbero y Bertranou, 2014). Asimismo, en la reorganización funcional, perdería espacio a su vez, el muy discutido Secretario de Transporte Ricardo Jaime en desmedro del ministro Julio De Vido.

En cuanto a la CNRT, en su art. 15, la mencionada Ley reforzó su rol de fiscalización y control en materia ferroviaria, en especial en los aspectos de mantenimiento y seguridad, incorporando además en su inciso h), la facultad de «resolver los conflictos que puedan plantearse entre la Administración de Infraestructuras Ferroviarias Sociedad del Estado, o la sociedad Operadora Ferroviaria Sociedad del Estado y las empresas concesionarias del servicio de transporte ferroviario". Adicionalmente en el art. 17, la Ley le encomienda al Poder Ejecutivo realizar las adecuaciones necesarias en las competencias de control y fiscalización del sistema de transporte automotor y ferroviario a cargo de la CNRT, lo cual habilitará a posteriori, su potestad para fiscalizar a operadores públicos.

El propósito de separación vertical nunca se llevó enteramente a cabo. Por un lado, la SOF no operó servicios de envergadura sino hasta fines de 2013, con la mencionada estatización de los servicios del Sarmiento metropolitano. Sorprendentemente, la SOF no asumió los servicios rescindidos previamente, tal como lo estipula la Ley y sólo se hizo cargo de algunos servicios interurbanos reintegrados a la gestión nacional luego de un período de provincialización. Por otro lado, la ADIF tampoco fue efectivamente la administradora de la infraestructura, dadas las concesiones integrales vigentes, y dada la falta de capacidades organizacionales para cumplir con esa función. Con fondos propios y créditos externos, ADIF encaró algunas obras de renovación de vías, pero también lo hizo SOF, contrariando la letra de la Ley.

El proceso de estatizaciones tuvo un nuevo hito con la sanción de la Ley 27.132 de 2015, también denominada Nueva Ley de Ferrocarriles Argentinos. 
La alta injerencia pública en el servicio metropolitano (subsidios cercanos al $90 \%$ del costo operativo, e inversiones recientes en infraestructura y material rodante después del siniestro de Once), convirtió a este segmento prácticamente en un servicio estatizado. Los sectores políticos y sindicales proclives a la estatización encontraron una nueva oportunidad para recrear la antigua empresa estatal FA. Al anuncio preliminar en el discurso presidencial del $1^{\circ}$ de marzo, le siguió en los días subsiguientes un proyecto de ley con componentes de escaso estudio: se modificaron algunas funciones de los entes preexistentes, se creó la empresa Ferrocarriles Argentinos Sociedad del Estado (FASE) como un holding de sociedades públicas y se habilitó la posibilidad de implementar un sistema de acceso abierto (Open Access) a la red de cargas (Bertranou y Serafinoff, 2019).

La nueva ley vino a convalidar el funcionamiento real de las sociedades creadas en 2008. En ese sentido, habilitó a la ADIF a actuar por sí o por terceros operadores en el mantenimiento o en las obras de infraestructura, así como a gestionar por sí o a través de los operadores, los sistemas de control de circulación de trenes que eventualmente su pudieran en marcha. Con respecto al Open Access, el desconcierto respecto a su implementación siguió reinando, más allá de una limitada reglamentación aprobada en 2018 (Decreto 1027).

Tal como se mencionó anteriormente, con su nuevo estatuto, la CNRT tiene la potestad de fiscalizar las actividades de las empresas (privadas) y operadores (públicos) de transporte automotor y ferroviario. Y con la creación en 2013 de la empresa BCyL SA (la cual no sólo asumió la gestión del ramal Belgrano de cargas, sino los ramales San Martín y Urquiza), el Estado concentró el 50\% de la red, aunque menos del 15\% de la carga transportada (Kohon, 2019).

En resumen, a partir de 2008 se incorporaron cuatro nuevas sociedades públicas a la trama institucional y empresarial ferroviaria, con una relación establecida con la CNRT: ADIF, SOF, BCyL y FASE.

\subsection{LAS NORMAS Y PRÁCTICAS DE FISCALIZACIÓN}

La función de control y fiscalización de la CNRT se cierne, entre otros, sobre los operadores estatales, así como sobre la ADIF. Los parámetros sobre los cuales se ejerce esta función no han sido siempre o no son actualmente suficientemente explícitos. Es conveniente de todas maneras analizar este ejercicio en cada uno de los casos, donde SOF ocupa un espacio protagónico.

La solicitud de la Ley 26.352 en cuanto a readecuar las competencias de fiscalización de la CNRT, y el reconocimiento en su nuevo Estatuto del nuevo escenario de empresas y operadores, se completa con la Resolución 
2210/15 del Ministerio de Interior y Transporte, que especifica y reglamenta lo dispuesto en materia de penalidades a operadores públicos. Establece los tipos de penalidades y sus secuencias, así como en su Anexo, identifica los 10 conceptos que son materia de fiscalización, 7 de los cuales corresponden a lo que se ha denominado calidad del servicio y los restantes 3 , a seguridad y mantenimiento. Cabe en este punto realizar algunas precisiones sobre el componente seguridad, sus condiciones de materialización y las normas que lo rigen en cuanto a su fiscalización, que no sólo afectan los servicios metropolitanos sino los de carga e interurbanos también.

En la fiscalización de todos los subcomponentes de seguridad y mantenimiento (vía y obras, material rodante, comunicación y señalamiento, energía eléctrica y prácticas operativas) se superponen distintos planos como el estado de la infraestructura (producto de las prácticas de mantenimiento y de las oportunas inversiones), la vigencia de un plexo normativo con parámetros explícitos para la fiscalización, y las capacidades de los distintos actores intervinientes (operadores, fiscalizadores, reguladores). La infraestructura ferroviaria argentina evidencia niveles avanzados de deterioro (Kohon, 2019; ITF-UNSAM, 2013) que son el producto de la falta de inversiones por parte del Estado y por parte de los concesionarios privados, la cual es a su vez, en parte, producto de la inestabilidad económica cíclica de la Argentina. El deterioro obliga a la readecuación de los estándares de fiscalización en un contexto en donde esos estándares son escasos, debido a la ausencia de normas o a la incertidumbre acerca de su vigencia. La Ley y el Reglamento General de Ferrocarriles son marcos vigentes y a la vez desactualizados, y numerosas normas técnicas de la época de FA ni siquiera están disponibles, o son impracticables (Bertranou, 2019). Los contratos de concesión establecieron parámetros que en la actualidad no pueden garantizarse. ${ }^{21}$

Con el objeto de intentar acotar el marco de incertidumbre, la CNRT dictó la Resolución 1770/08 que obliga a todos los operadores (ahora públicos y privados) a presentar sus planes de mantenimiento para el año siguiente, lo cual permite la posibilidad de constatar las acciones y elaborar un informe anual que incluya indicadores del estado de la red y del material rodante. ${ }^{22}$

La precariedad de la normativa técnica ferroviaria llamó la atención de las autoridades nacionales. Por Resolución 76/17 del Ministerio de Transporte se creó la Comisión Nacional de Normas y Especificaciones Técnicas de Ferrocarriles, la cual quedó integrada por tres profesionales del sector. Como un primer producto, esta Comisión preparó la Directiva de Seguridad Operacional (Res. MT 170/2018). ${ }^{23}$ Gracias al empuje del Decreto 2017/18, que entre otras cues- 
tiones encomienda al Ministerio actualizar la normativa ferroviaria, la Comisión participa también en la elaboración de la «Norma sobre requisitos de la vía para la seguridad y mantenimiento en el transporte ferroviario" (Res. SGT 87/19). Lo paradójico de esta última norma es que establece criterios que son de dudosa aplicación práctica y pondrían a todo el sistema ferroviario en una situación de parálisis. Los avances realizados no han sido positivos y en materia de seguridad y mantenimiento, la mencionada Res. 2210 agrega obligaciones (informes semestrales) sin valor agregado a los informes anuales de cumplimiento de los planes de mantenimiento. Y las normas técnicas siguen inexistentes, confusas o impracticables a la luz del deterioro de la infraestructura.

En lo referente a calidad del servicio, la Res. 2210 aporta un marco más concreto de actuación para la CNRT, marco que se completa con las Res. CNRT 634 y 1367/16 ${ }^{24}$ que están bajo la responsabilidad de la Gerencia de Fiscalización de Gestión Ferroviaria ${ }^{25}$. Las actuaciones e informes de ambas Gerencias son independientes, lo cual refuerza cierta fragmentación institucional en el tratamiento ferroviario. ${ }^{26}$

Las penalidades aplicadas a la empresa estatal SOF, como se aprecia en la Tabla 1, se ponen en práctica recién a partir de 2016, cuando se termina de establecer el marco de fiscalización de servicio al operador estatal en el ámbito metropolitano. Esto implica que, desde fines de 2013, cuando la empresa se hace cargo de la operación de la línea Sarmiento y hasta entrado el año 2016, la CNRT no pudo establecer penalidades en su fiscalización del servicio debido a la ausencia de un marco legal. Si se comparan datos recientes de aplicación de penalidades a SOF y a las dos concesionarias remanentes, sorprende que la primera, con cerca del $89 \%$ de los pasajeros transportados y $84 \%$ de trenes$\mathrm{km}$ recorridos, tenga menos penalidades que las dos últimas sumadas. Cabe mencionar también que, si se considera uno de los indicadores de calidad, la regularidad absoluta, la diferencia es levemente a favor de las empresas privadas combinadas respecto de SOF $(80,7 \text { contra } 79,3 \%)^{27}$. Si bien a SOF no le caben las multas pecuniarias, la diferencia es amplia, en especial si se considera que muchos de los llamados de atención a la empresa estatal, pueden constituir multas en el caso de las concesionarias. 


\section{Tabla 1.}

Sanciones a SOF y las concesionarias remanentes (cantidades)

\begin{tabular}{lll}
\hline Año & SOF & Concesionarias \\
\hline 2016 & 22 & 170 \\
\hline 2017 & 67 & 95 \\
\hline 2018 & 78 & 86 \\
\hline $2019^{*}$ & 53 & 87 \\
\hline
\end{tabular}

*Hasta octubre

Fuente: elaboración propia en base a datos de CNRT

El desempeño de la CNRT en el control y fiscalización de los operadores públicos ha sido fuertemente cuestionado por la SOF. Un caso emblemático es el recurso de reconsideración (con alzada en subsidio) contra la Resolución 827/2017 de la CNRT, por parte del operador público.

Mediante la mencionada resolución, la CNRT sancionó a la SOF con un llamado de atención por "suministro de información errónea a los usuarios..." y por "...incumplir las órdenes emitidas por esta Autoridad de Control...", en el caso de uno de sus servicios regionales (Salta-Güemes). La respuesta del operador público fue el mencionado recurso de reconsideración en alzada tramitado el 31 de julio de $2017^{28}$.

Los argumentos de la Operadora son principalmente dos. Primero, que la CNRT no tiene la competencia para dictar una resolución como la mencionada, lo cual afirma el carácter inconstitucional de su proceder. Segundo, porque “... por aplicación del principio de unidad de acción que debe guiar las relaciones interadministrativas, y de los deberes de coordinación y colaboración que se derivan de aquel, resulta contrario a la lógica y el buen sentido admitir que el Estado y sus entidades puedan aplicarse sanciones, máxime cuando la actividad de la Administración se encuentra siempre enderezada a la satisfacción del bien común" (Recurso de Reconsideración mencionado anteriormente).

Los servicios jurídicos de la SOF (nutridos en gran medida de los servicios jurídicos de las concesionarias, acostumbradas a pleitear contra el Estado), entendieron (y hasta ahora lo siguen haciendo), que por la Ley 26.352, la CNRT no tiene competencia sobre operadores públicos, por lo que el Decreto 1661/2015 y la Resolución Ministerial 2210/15 son inconstitucionales, en la 
medida en que desnaturalizan lo que una norma de orden superior ha establecido en cuestiones de fiscalización de la actividad ferroviaria.

En defensa del segundo argumento, "...las relaciones interadministrativas como la que vincula a esta Operadora con la CNRT... son de coordinación y colaboración, razón por la cual, en ellas se encuentran ausentes podres jurídicos exorbitantes propios de aquellas relaciones que se establecen entre el Estado y los particulares... En estas relaciones intersubjetivas está ausente el régimen jurídico exorbitante propio de los actores del derecho administrativo, puesto que no cabe admitir en ese plano enfrentamientos entre entidades que tienen la posibilidad de ejercer prerrogativas de poder público... En ese sentido... en la esfera de las relaciones de naturaleza interadministrativa, no resulta procedente la aplicación de multas de carácter penal o administrativo" (Recurso de Reconsideración, nota 26). Muchos dictámenes de la Procuración del Tesoro de la Nación son citados en defensa de este argumento. ${ }^{29}$

La respuesta de la CNRT confirmando la sanción (no pecuniaria, por cierto), se basa en la primacía del usuario (Art $42^{\circ}$ de la Constitución Nacional); en el carácter de Empresa Nacional de la SOF (artículo $3^{\circ}$ de la ley 2.873 de Ferrocarriles) y que como tal se encuentra sujeta a las previsiones reglamentarias y con ello al régimen de faltas que establezca el Poder Ejecutivo Nacional (artículo 94 de la ley 2873); y en el artículo $17^{\circ}$ de la Ley 26.352, que establece que el Poder Ejecutivo Nacional podrá realizar las adecuaciones necesarias en las competencias de control y fiscalización del sistema de transporte automotor y ferroviario a cargo de la CNRT o del organismo que en el futuro lo reemplace (énfasis propio).

Lo que llama la atención en este conflicto extendido es el grado de desorganización del sistema ferroviario, cuando uno de los agentes más importantes impugna la función de otro de los agentes imprescindibles, sin que haya una intervención clara del Ministerio de Transporte para esclarecer los alcances de los roles de cada uno de los actores intervinientes (Bertranou, 2019).

Si bien SOF ha sido el objeto más relevante de fiscalización por parte de la CNRT, existe una actividad dirigida a los otros actores públicos. Por lo pronto, la mencionada resolución 2210/15 se aplica a Ferrocarriles Argentinos SE y «sus sociedades controladas": SOF, ADIF y BCyL. En el caso del BCyL, la fiscalización se circunscribe a la verificación de los requisitos de seguros y de mantenimiento de inventarios, además de los aspectos de mantenimiento y seguridad, sobre los cuales ya ha habido un tratamiento en los párrafos anteriores. En el caso de ADIF, la CNRT no ejerce de manera directa ningún tipo de control.

Un aspecto importante en el caso de la empresa BCyL es que no existe un inventario actualizado de bienes e infraestructuras a su cargo. Se intentó 
subsanar esta deficiencia con un contrato con la Universidad Nacional de La Plata, pero los resultados fueron insatisfactorios. En 2019, el Ministerio emitió una resolución que conmina a la empresa, a la CNRT y a ADIF a hacer el inventario, sin asignar partidas para ello. Actualmente, este relevamiento está suspendido. Al no haber qué controlar, la actividad de fiscalización de la CNRT se ve limitada a los aspectos de seguridad, y los intentos de aplicar alguna penalidad se han topado con el rechazo de la empresa, la cual alega no poder comprobar que los bienes identificados le pertenezcan. En un informe reciente de la $\mathrm{CNRT}^{30}$, BCyL no consigna información operativa ni de bienes (contrariamente a los operadores privados) y se observan penalidades para los concesionarios privados, pero no para el operador público. La empresa tampoco tiene compromisos de inversión, más allá de que se ha visto fuertemente beneficiada por renovaciones integrales de vía en el ramal Belgrano y con proyecciones al San Martín.

Finalmente, la CNRT no fiscaliza a la ADIF de manera directa. La CNRT entiende que ADIF todavía no cumple plenamente con las funciones que tiene establecidas en su normativa: no ejerce la administración de la infraestructura (lo hacen los operadores privados o públicos) ni tampoco controla el tráfico ferroviario. La cuestión de la administración de la infraestructura muestra el grado de desorden que existe en el sistema argentino, más allá de que existe la regla general de que la administración de hecho está a cargo de los operadores (concesionarios, por derecho y también los operadores públicos), con o sin delegación explícita de ADIF, siguiendo lo establecido en la Ley 27312. Existen, sin embargo, distintas situaciones: en la línea Sarmiento metropolitana, a la SOF se le transfirió la operación y la infraestructura; en la línea a Mar del Plata, ADIF le transfirió la gestión de la infraestructura a la SOF (como lo permite la Ley); y en la línea a Rosario a cargo de la empresa NCA (Nuevo Central Argentino), la ADIF ejecutó obras de manera directa, que el concesionario se niega a recibir, porque rebasan lo que tenía asignado en los pliegos originales. En suma, la situación carece de una visión de conjunto que contemple un modelo claro de operación de un sistema ferroviario.

La fiscalización a ADIF que hace la Gerencia de Fiscalización Técnica Ferroviaria es indirecta, es decir, a través de los operadores cuando ADIF está ejecutando obras en los ramales a su cargo. En esos casos, la CNRT interpela al operador de manera directa sobre alguna observación de seguridad en las obras, y éste en todo caso, se relaciona con la ADIF. 


\section{BALANCE Y PERSPECTIVAS DE LA FUNCIÓN DE CONTROL}

La experiencia reciente de la CNRT en la fiscalización de empresas o agencias públicas ha aportado alguna evidencia que puede permitir hacer una valoración de su desempeño a la luz de otras experiencias similares. La caracterización de este desempeño depende de todas maneras, de distintas dimensiones de análisis, que necesitan ser consideradas para poder pensar y diseñar un sector público cada vez más eficaz en el cumplimiento de sus mandatos. En este apartado final se evocarán estas dimensiones, así como se plantearán algunos ejes para la futura organización institucional del sector.

Un primer aspecto tiene que ver con los marcos legales y operativos para poder llevar adelante la función de fiscalización. Estos marcos tienen algunas particularidades en el caso ferroviario y según sea la empresa o agencia en cuestión. Por lo pronto, está la distinción entre las dimensiones de calidad del servicio y las dimensiones incluidas en el concepto de seguridad. En cuanto al seguimiento de la calidad del servicio, con mucho retraso, los estándares referidos a la SOF se fueron precisando en sucesivos instrumentos legales. Resulta controversial, sin embargo, la impugnación que ha hecho la empresa a la potestad que legalmente tiene la CNRT de hacer su seguimiento y de realizar los señalamientos necesarios. En cuanto al BCyL, los acotados componentes del servicio no pueden ser supervisados por la falta de información básica, que se prolonga ya por casi siete años. En cuanto a seguridad, los estándares son ambiguos o simplemente inalcanzables dado el nivel de la infraestructura. La obligación, en general cumplida, de proporcionar un plan de mantenimiento, habilita la realización de señalamientos por parte de la CNRT, pero no esconde el hecho de que la infraestructura acumula déficits cuantiosos, tanto en la vía, como en el material rodante y en las tecnologías. Por último, el caso de la ADIF revela un nivel alto de desorganización institucional, ya que sus roles están desdibujados y, por ende, la pertinencia de algún tipo de fiscalización puede ser discutida o es inviable. En resumen, los marcos legales y operativos tienen limitaciones en cuanto a los parámetros, en algunas facetas son impracticables y se manifiestan impugnaciones en cuanto a las competencias institucionales. El panorama no es auspicioso para una actividad de carácter industrial como es la ferroviaria (Müller, 2018), que es un ejemplo de lo que la bibliografía denomina Large Technical Systems (Mayntz y Hughes, 1988), que por sus características y los riesgos que su actividad puede representar, requieren de esfuerzos sostenidos de dotación de mayor confiabilidad (Cantero y González, 2015).

Un segundo aspecto está ligado estrechamente al anterior, y tiene que ver con las capacidades del organismo fiscalizador, en este caso, la CNRT (Bertra- 
nou, 2015). Este trabajo no estudia de manera sistemática las capacidades del organismo, aunque alude tangencialmente a ellas, pero se advierte en las entrevistas que las capacidades para fiscalizar todos los servicios y la amplia red (aunque esté parcialmente desactivada), tanto de gestión pública como privada, es insuficiente. Por un lado, está la cuestión de los componentes organizacionales de la capacidad, recursos humanos, financiamiento, tecnologías, procesos, entre otros aspectos. Las dotaciones para el control de los parámetros de seguridad están radicadas en Buenos Aires, lo que limita la supervisión en todo el territorio nacional. Ha habido, sin embargo, avances en las dotaciones y tecnologías de seguimiento en materia de calidad en el área metropolitana. La posibilidad de avalar los planes de seguridad operacional que presenten los distintos operadores es de muy difícil realización. Por otro lado, la capacidad también debe analizarse en términos de las competencias del organismo para asegurar la continuidad de sus procesos de fiscalización y sanción. En ese sentido, en el ámbito ferroviario, la CNRT carece de los dispositivos legales para hacer que sus disposiciones se cumplan de manera inmediata.

En tercer lugar, es válida la discusión acerca de si deben mantenerse separadas en otro organismo, las funciones de fiscalización de los servicios y la infraestructura. Sobre este punto existen opiniones diferentes, más allá de cómo estén plasmadas en el ordenamiento legal. Por un lado, hay quienes sostienen que la recreación de los operadores estatales le resta margen de acción a los organismos independientes de fiscalización, ya que la responsabilidad desde el punto de vista del Estado estaría asentada en la nueva empresa de servicios. En el caso ferroviario, se admitiría que un organismo externo fiscalice lo relativo al mantenimiento y la seguridad, pero se entendería que la calidad del servicio es responsabilidad de la propia empresa prestadora y en segunda instancia, sería responsabilidad de otros institutos de protección de los derechos de los usuarios como son las Defensorías del Pueblo. Este es el caso español, donde la calidad del senvicio es responsabilidad primaria del operador público RENFE. El organismo de fiscalización ferroviaria sólo hace la supervisión de los estándares de seguridad, a cargo de los operadores como de la Administradora de Infraestructura (ADIF española).

Otra posición se funda en la constitucionalidad de los derechos de usuarios (art 42 y 43, CN), y en la homogeneidad requerida en la prestación de los servicios públicos, más allá de los territorios y de qué figura jurídica sea la responsable de las prestaciones. Esta homogeneidad en la calidad de los servicios puede ser garantizada, entre otras medidas, por un organismo cuyo propósito central sea el de verificar el cumplimiento de los marcos regulatorios y 
planes de provisión de los servicios, así como de las condiciones de seguridad. Este organismo debería incorporar la voz de los usuarios, tal como lo establece el art 42. El organismo podría no ejercer funciones regulatorias, en especial económicas, aunque sería conveniente que ejerciera un abanico de funciones de normalización técnica. Esta diversificación organizativa y especialización funcional remite a la tendencia observada en los últimos años de creación de organismos con funciones más restringidas en el marco de lo que se ha mencionado como "purificación" de roles.

No es un contrasentido que, en un contexto de diversidad institucional y especialización funcional, donde cada organismo debe cumplir con su rol en el marco de una integración y coordinación funcional y operativa general de un sector, una agencia pública controle e impugne a un operador público; lo que está en juego es que cada uno de estos organismos cumpla sus mandatos para beneficio de los usuarios o ciudadanos en general. En el cumplimiento de los roles institucionales deben existir mecanismos de control, y las agencias especializadas en esto último, deben tener todos los medios para ejercer eficazmente esta función, en beneficio nuevamente, de los ciudadanos. Estos medios aluden a la capacidad y a la factibilidad de aplicar sanciones por los incumplimientos, los cuales deben aplicarse a los operadores como empresas, y a los o las gerentes responsables de las decisiones, con las características que la ley establezca en cada caso. Puede discutirse la pertinencia de la aplicación de multas pecuniarias, al amparo de una discutida noción sobre la unidad del tesoro público. Sin embargo, el presupuesto público es un conglomerado de fondos, y la aplicación de multas a empresas públicas puede incentivar la mejora del cumplimiento, así como proveer eventuales recursos adicionales a los organismos de control.

En el caso de que existan discrepancias entre los organismos en cuanto a la interpretación sobre los contenidos de sus interrelaciones, el propio ordenamiento institucional debería establecer la forma de su resolución, sea por la vía de la supervisión administrativa (ministerial o presidencial), o complementariamente, por la vía de una entidad externa de naturaleza jurisdiccional. El caso de los ferrocarriles alemanes aporta elementos de juicio para esta discusión (Lazcano, 2016). En Alemania, sintéticamente, el sector ferroviario cuenta con operadores públicos (Deutsche Bahn Mobility \& Logistics como el más importante) y privados, con un administrador público de la infraestructura (Deutsche Bahn Netz), con una Agencia Federal de Redes, que supervisa la administración de las redes y las eventuales prácticas discriminatorias de sus operadores y con la Oficina Federal de Ferrocarriles, organismos de regulación, 
habilitación, supervisión de inversiones y aplicación del programa de subsidios, entre otras funciones. La variedad de organismos estatales no impide que cada uno de ellos ejerza su función respectiva. La Agencia Federal de Redes tiene la potestad de acudir a la Oficina Antimonopólica o a la Justicia Federal por las eventuales prácticas monopólicas o discriminatorias de la DBNetz.

Una cuarta dimensión en juego vinculada con lo anterior, tiene que ver con la cultura política o la cultura del sector público en general, y cómo se relacionan los y las representantes de la alta gerencia pública y política en el cumplimiento de los marcos que reglan la actividad de las agencias públicas. ${ }^{31}$ En este punto hay varias dimensiones a considerar: a) el peso político diferente de algunos funcionarios públicos en la red de agencias en un sector determinado (esta diferencia luego se traslada a la relevancia o no de la agencia); b) la predisposición de los y las funcionarias a entablar acciones conjuntas interorganizacionales, lo cual no implica descuidar los mandatos que cada una de estas agencias tienen; c) la predisposición de los y las funcionarias a cumplir los mandatos institucionales con relativa autonomía, buscando elevar la calidad de la gestión pública; d) la autolimitación de los altos funcionarios y funcionarias públicas en relación con los alcances de sus funciones de supervisión de las agencias públicas que dependen jerárquicamente; e) el conocimiento o experiencia (o no) previa que sobre el área respectiva tengan los funcionarios entrantes, entre otras facetas o manifestaciones del comportamiento público derivado de esta cultura política. Un marco de reglas que puede ser claro para organizar el accionar combinado de distintas agencias en un sector, puede ser fácilmente sobrepasado por una cultura o práctica política de patronazgo, de extralimitación de funciones o de aceptación de estándares operativos más bajos que tienden a debilitar la gestión de un servicio. En el caso de la CNRT, sus potestades de fiscalización y sanción de los operadores ferroviarios privados fueron bloqueadas por las autoridades superiores durante muchos años, lo cual perjudicó la calidad de los servicios. Con la inauguración de operadores estatales a partir de 2013, y sobre todo en la gestión del Gobierno de Cambiemos (2015-2019), la eficacia de su fiscalización fue disputada por operadores cuyas gerencias gozaron de mayor cercanía con el poder político (SOF, ADIF y BCyL) comparada con la de la propia CNRT, relegada a un plano de actuación técnica, pero con escasa influencia en las orientaciones generales del sector. De manera complementaria, la cultura pública vive como una "traición" los señalamientos de un organismo del Poder Ejecutivo a otro y, por consiguiente, alienta un comportamiento colectivo que nivela hacia abajo los estándares de desempeño. La ausencia de contratos programa o acuerdos de 
operación entre los ministerios y las agencias y organismos descentralizados, debilita la posibilidad de establecer las pautas de interrelación necesaria para la prestación de los servicios públicos.

Una quinta dimensión de análisis tiene que ver con la forma en que se acompasan los estándares de fiscalización (pública o privada) con los niveles de inversión en infraestructura y material rodante, que en el ámbito ferroviario son cruciales para la seguridad y la calidad del servicio. Esta cuestión rebasa el objeto más acotado de este trabajo, pero hace a las condiciones de desarrollo de un sistema de fiscalización y de sanciones que sea apropiado a las condiciones propiamente físicas de provisión de los servicios. Los estándares de seguridad y parámetros operativos se fijan de acuerdo con estándares de mantenimiento e inversión, especialmente en una industria como la ferroviaria. Exigir estándares y fiscalizar en consonancia no son actividades aisladas. La situación de la infraestructura y su mantenimiento deben ser discutidas abiertamente, y los parámetros operativos deben ser ajustados a esa situación, por razones de seguridad. Esto no quiere decir que no puedan activarse otros ámbitos de mejora como los de los procesos organizaciones. La fiscalización debe alertar sobre las deficiencias, así como ajustar sus exigencias a las condiciones de seguridad existentes.

Este análisis debería iluminar la puesta en marcha de ciertas modificaciones institucionales, operativas y culturales asociadas a la prestación de los servicios públicos y a los roles que a todos los organismos públicos le caben. Un punto central tiene que ver con el foco prioritario en todo el proceso de evaluación de este desempeño organizacional: el y la usuaria de los servicios de pasajeros, o el y la generadora de cargas. Muy especialmente el y la usuaria de los servicios, ya que confía que los organismos estatales intervinientes han razonablemente evaluado las condiciones de prestación de los servicios y han habilitado el uso de equipos y tecnologías, independientemente de quién sea el prestador del servicio, una empresa estatal o privada. Un ciudadano o ciudadana toma decisiones de movilidad en función de los fines que persigue y no se detiene a indagar si la prestación del servicio la realiza una empresa privada o pública. En ese sentido, las autoridades públicas deben elaborar marcos regulatorios, estándares operativos, acuerdos de operación, esquemas de financiamiento y normas técnicas considerando el interés de los usuarios actuales y potenciales, no en el interés de las empresas y sus directivos o directivas, incluidas las estatales.

La pluralidad de organismos en un marco de orden y de interrelaciones preestablecidas y supervisadas, es un arreglo que puede aportar numerosas ventajas a los destinatarios y a la planificación pública en general y el cumpli- 
miento de todas las condiciones necesarias. Esta era una de las preocupaciones esbozadas tempranamente en el trabajo de Nahón y Bonfiglio (2007), cuando la tensión entre organismos de control y operadores públicos se gestaba. Esto implica, por un lado, definir los organismos y delimitar e interrelacionar sus competencias, considerando el conjunto de funciones que deben ser cumplidas para que un servicio público se mantenga en condiciones de calidad y sostenibilidad. Por otro lado, es necesaria la explicitación de los términos de la interrelación organizativa y funcional, estableciendo acuerdos programa o acuerdos de operación con las autoridades políticas, y esclareciendo los mecanismos políticos y administrativos para asegurar la gobernanza global del sector y para resolver los conflictos interagenciales.

El sector ferroviario argentino requiere de cambios organizacionales. Algunas primeras ideas son las siguientes: a) escindir el segmento ferroviario de la CNRT y crear una Agencia de fiscalización y normalización ferroviaria con competencias sobre la seguridad y la calidad de los senvicios; b) suprimir la ADIF y llevar las funciones de planificación de la infraestructura ferroviaria al Ministerio (esto supone que el acceso abierto no se podrá implementar y que los operadores serán responsables del mantenimiento de la infraestructura que les sea asignada); y c) fortalecer el área central ferroviaria del Ministerio en materia de planificación, diseño de políticas y regulación; entre otros cambios importantes.

La nueva Agencia ferroviaria deberá concentrar funciones de fiscalización y normalización, y podrá incluir funciones de homologación/certificación de equipos, tecnologías y competencias ${ }^{32}$. En cuanto a la fiscalización, deberá contar con la potestad de aplicar las penalidades correspondientes a empresas y gerencias, públicas o privadas, incorporando un procedimiento ejecutivo y los medios adecuados para su ejercicio.

Finalmente, será necesario promover otra cultura institucional y política, donde se promueva la colaboración interinstitucional pero basada en el mejoramiento de los estándares de calidad de los servicios, y donde se promueva la circulación de saberes técnicos y gerenciales apropiados a las distintas funciones que requieren ser cumplidas. 


\section{NOTAS}

1 El autor agradece los comentarios de Juan Arrarás, Ana Da Viá, Horacio Faggiani, Carlos Leguizamón, Marcos Polcri, Mariela Rocca, Jorge Sánchez, Guillermo Schweinheim, Pablo Vazano y dos lectores/as anónimos/as de la Revista.

2 Denominado también, responsabilización, como la obligación de rendir cuentas por parte de organismos y funcionarios/as, o respondibilidad (Oszlak, 2003), como una obligación de rendir cuentas que tiene como primera dirección de exigencia la impuesta por el propio sujeto obligado. ${ }^{3}$ El trabajo pionero de Henri Fayol (1971) reconoce la universalidad de la administración y define cinco elementos básicos de la misma: planificación, organización, dirección, coordinación y control, con las siguientes características: a) la planificación consiste en examinar el futuro y elaborar un plan de acción, b) la organización consiste en construir una estructura dual (material y humana) para conseguir los fines, c) la dirección consiste en el mantenimiento de la actividad entre el personal de la organización (motivación y estímulo), d) la coordinación consiste en la cohesión, integración y armonía de toda la actividad y el esfuerzo, y e) el control consiste en constatar que todo haya sido efectuado en conformidad con el plan establecido. Clásicos como Luther Gulick (1930 [1997]) en sus Notas sobre Teoría de la Organización y Herbert Simon (1937[1997]) en sus Proverbios de la Administración, aluden a la función de control en el marco de la creciente especialización y la necesidad de coordinación de una variedad creciente de organizaciones administrativas.

${ }^{4}$ El término más adecuado es el de Auditoría Interna. El control interno refiere principalmente a una responsabilidad gerencial de asegurar el cumplimiento de las normas, lo cual lleva a la intervención de los servicios jurídicos de la organización.

${ }^{5}$ Existe otra organización en el sector, Desarrollo del Capital Humano Ferroviario Sociedad Anónima de Participación Estatal Mayoritaria, que no está bajo la supervisión de la CNRT, y que fue creada con el objeto de diseñar, organizar, promover y realizar actividades de asistencia técnica, asesoría, capacitación, formación y recalificación y gestión de recursos humanos, fortalecimiento organizacional y resguardo documental en materia ferroviaria.

${ }^{6}$ Apartado basado en Bertranou (2013).

${ }^{7}$ Si bien no hay estudios completos en la Argentina, el trabajo de Alessandro y Gilio (2010) analiza cerca de 80 agencias autónomas estableciendo diferencias en función del origen ejecutivo o legislativo de su creación. El estudio de Oszlak y otros (2001) menciona más de 70 organismos, "...sin contar empresas públicas (casi todas privatizadas o eliminadas), universidades nacionales, bancos oficiales" (p. 2). Por otro lado, puede revisarse el listado ofrecido por López y Rubins (2012).

8 Otra de las innovaciones organizacionales utilizadas para facilitar la ejecución de políticas y programas ha sido la creación de las Unidades Ejecutores ligadas a la implementación de los préstamos de los organismos multilaterales de crédito. Un análisis de los problemas derivados de esta innovación puede verse en Martínez Nogueira (2002).

${ }^{9}$ Economías de escala, economías de alcance, elevados requerimientos de inversión física y demanda relativamente inelástica (Nahón y Bonfiglio, 2007: 1098).

10 Ver Majone y La Spina (1993) para un análisis de las alternativas (menos eficaces) a la regulación.

${ }^{11}$ Consagrados contemporáneamente en la nueva Constitución Nacional de 1994, Art. 42 y 43. 12 Los organismos tienden a diferenciar estas funciones: el control es más general, de las condiciones legales del servicio y de las condiciones de las empresas, y la fiscalización es el acto de verificación, muchas veces in situ, de las condiciones de prestación del servicio o de las redes. En este artículo se utilizarán de manera indistinta para aludir a la función de control.

13 Proceso que Laegreid y otros (2008) Ilaman de purificación de roles (role purification).

14 Ferrocarriles Metropolitanos S.A., Decreto 502/90.

15 La CNRT lleva adelante también una gama importante de funciones de gestión, muchas de 
las cuales podrían entenderse como parte de su tarea de fiscalización, como las habilitaciones de vehículos, y otras que le fueron asignadas por contar con una mayor dotación de personal, como fue la determinación del subsidio al gasoil. ${ }^{16}$ En este trabajo se usará de manera genérica el término control, aunque la normativa menciona los términos fiscalización y control. Si bien no hay una clara distinción de estos conceptos en las normas, el control refiere a una actividad más general de supervisión de las actividades de los operadores en el marco de sus contratos y la fiscalización remite a las actividades en terreno de inspección y verificación del cumplimiento de las normas.

17 Sus nombres actuales son: Gerencia de Fiscalización de Gestión Ferroviaria y Gerencia de Fiscalización Técnica Ferroviaria.

${ }^{18}$ Art. $8^{\circ}$. A los fines del control de la gestión del transporte ferroviario bajo su jurisdicción, tendrá como objetivo fiscalizar las actividades de las empresas y operadores ferroviarios, en cuanto al cumplimiento de las obligaciones que surgen de la normativa aplicable. Art. $9^{\circ}$. En lo relativo al control técnico del transporte ferroviario, tendrá como objetivo controlar el cumplimiento de las normas vigentes, respecto de la infraestructura fija y del material rodante (énfasis propio).

${ }^{19}$ Este tema será tratado de manera más extensa en el apartado siguiente.

20 Informe interno de la Gerencia de Asuntos Jurídicos, CNRT.

${ }^{21}$ Cabe en este punto recordar que la propia noción de seguridad es debatida en todo el mundo, y los criterios de operacionalización de este principio son diversos según los países, incluso al interior de la Unión Europea. De todas maneras, estos países han especificado mejor los parámetros de desempeño en materia de mantenimiento y seguridad, y en la medida en que no se ha interrumpido la inversión pública, como en la Argentina, es materialmente posible cumplir con los parámetros identificados.

22 El informe lo elabora la actual Gerencia de Fiscalización Técnica Ferroviaria.

${ }^{23}$ Este instrumento se constituye en un primer hito de un Sistema Nacional de Gestión de la
Seguridad Operacional. La Resolución designa a la CNRT como la agencia que debe verificar el cumplimiento de lo establecido en los art. 4 y 5 , a saber, que todas las empresas y operadoras ferroviarias, así como la ADIF, cuenten con una unidad de nivel gerencial de seguridad operacional, que elabore e implemente un Sistema de Gestión de Seguridad Operacional en acuerdo con la primera Directiva. Se estableció como fecha tope para cumplimentar estas disposiciones el 31 de marzo de 2019. Por el momento, las empresas están en la etapa de identificación de los responsables, y salvo algunos casos, los planes no han sido aún elaborados. La CNRT debe validar estos planes, aunque carece de los recursos humanos suficientes para emitir un juicio inequívoco sobre la calidad y viabilidad de estos planes.

24 Res. 634/junio de 2016: Metodología de control de servicios de pasajeros y cargas regionales y larga distancia. Involucra GCGF y se identifican indicadores de primer y segundo orden y algunos registros tipo. Res. 1367/diciembre de 2016: Indicadores de calidad de los servicios de pasajeros de larga y metropolitanos, y aprueba el procedimiento de aplicación de una sanción. 25 Ex Gerencia de Concesiones Ferroviarias y Gerencia de Control de Gestión Ferroviaria.

${ }^{26} \mathrm{El}$ procesamiento de las inspecciones que luego pueden dar lugar a penalidades se hace de manera independiente entre las Gerencias. En el caso de la GFTF, se hace un Ilamado de atención por empresa, por semestre y por cada una de las especialidades del mantenimiento y seguridad: vía y obras, señalamiento y comunicaciones, energía eléctrica y prácticas operativas.

${ }^{27}$ Datos de CNRT. https://www.argentina.gob.ar/ transporte/cnrt/estadisticas-ferroviarias

${ }^{28} \operatorname{Exp~N} N^{\circ}$ S02:66649/2017.

29 PTN, 246:352 (...) Por lo demás, una elemental regla "de Derecho Procesal indica que "NO cabe concebir la existencia de un proceso contencioso con una sola parte..." (Palacio, Lino Enrique: "Derecho Procesal Civil», AbeledoPerrot, Buenos Aires, 1979, T» III, pág. 13), de donde cabe preguntarse si puede el Estado enfrentarse a sí mismo en un litigio judicial. La respuesta debe ser necesariamente negativa, dado 
que "Ciertamente, el Estado Nacional y aun la Administración Pública, más allá de toda disquisición relativa a su organización administrativa y descentralización, sea orgánica o funcional, debe ser rigurosamente entendido como una unidad institucional, teleológica y ética..." (Dictámenes: 19Qr103), siendo que “... la relación de identidad del Estado Nacional en las diversas formas que modernamente reviste para el cumplimiento de fines especiales ha sido declarada en diversos pronunciamientos por la Corte Suprema de Justicia de la Nación..." (Dictámenes: 190s187; v. Fallos: 252:375 y 273:III).

30 Informe Desempeño Red Ferroviaria 2018, CNRT.

${ }^{31}$ En relación con el concepto de cultura política o del sector público me refiero al conjunto de actitudes, valores y conocimientos que comparten en general los miembros de una comunidad política, y que refieren a cómo debe ser el funcionamiento de esta última y los desempeños de cada uno de sus miembros. El concepto tiene un parecido con el de matriz política (Acuña y Chudnovsky, 1993), en tanto medio o ambiente donde una actividad ocurre, constituido por distintas variables sociopolíticas e ideológico-culturales, que brinda a los actores un conocimiento de cómo funcionan y deberían funcionar las relaciones sociales, cuál es el marco de interpretación de sus intereses y cuáles pueden ser cursos de acción a emprender. 32 Es posible también pensar en la creación de una agencia para estos fines o en una coordinación con el OAA (Organismo Argentino de Acreditación) para la acreditación de empresas e instituciones que puedan garantizar las certificaciones y homologaciones necesarias. El control de estos requisitos estaría en la competencia de la agencia ferroviaria.

\section{BIBLIOGRAFÍA}

Acuña, Carlos y Mariana Chudnovsky (2013). "Cómo entender a las instituciones y su relación con la política: lo bueno, lo malo y lo feo de las instituciones y los institucionalismos", en Acuña, Carlos (comp.), ¿Cuánto importan las instituciones? Gobierno, estado y actores en la política argentina, Buenos Aires, OSDE/Siglo XXI.

Alessandro, Martín y Andrés Gilio (2010). "Cuando el origen importa: presidentes y congresos en la creación de organismos descentralizados en la Argentina (1983-2009)", Revista del CLAD Reforma y Democracia, № 48, octubre, Caracas.

Azpiazu, Daniel, Nicolás Bonfiglio y Carolina Nahón (2008). Agua y energía: mapa de situación y problemáticas regulatorias de los servicios públicos en el interior del país, Documento № 18, Economía y Tecnología, FLACSO Argentina.

Barbero, José y Julián Bertranou (2014). "Estado, instituciones y política en el transporte público", en Acuña, Carlos (comp.) (2014, en prensa), Dilemas del Estado Argentino. Fortalezas y debilidades de la política exterior, las políticas económicas y de infraestructura, Buenos Aires, Siglo XXI - Fundación OSDE.

(eds.) (2019). Las políticas de transporte en la Argentina. Los años de la post Convertibilidad (2002-2015), Buenos Aires, Editorial Biblos. 
Bertranou, Julián (2011). «Estado y agencia público-privadas en la promoción del desarrollo productivo en la provincia de Mendoza" Documentos y Aportes en Administración Pública y Gestión Estatal, Vol. 11, №17, 2011, pp. 6-20. UNL, Santa Fe, Argentina.

(2013). "Creación de agencias especializadas, capacidad estatal y coordinación interinstitucional», Revista Perspectivas de Políticas Públicas, Año 2, № 4.

(2015). "Capacidad estatal: revisión del concepto y algunos ejes de análisis y debate", Revista Estado y Políticas Públicas, № 4, FLACSO Argentina, http://politicaspublicas. flacso.org.ar/revista

(2019). «(Des)organización estatal y política pública en Argentina. Desarrollo conceptual y análisis del transporte ferroviario", Revista POSTData, Vol 24 № 1, abril.

Bertranou, Julián y Valeria Serafinoff (2019). «Organización institucional del sector transporte», en Barbero, José y Julián Bertranou, eds., op. cit.

Bresser Pereira, Luiz Carlos (1999). Reforma del Estado para la Ciudadanía. La reforma gerencial brasileña en la perspectiva internacional, Buenos Aires: Eudeba/CLAD.

Cantero, Javier y Natalia González (2015). «De la naturaleza y especificidad del sistema ferroviario argentino: el desafío de la confiabilidad", Ciencias Administrativas, núm. 6, juliodiciembre, pp. 83.

Christensen, Tom y Per Laegreid (2007). "Reformas post Nueva Gestión Pública», Gestión y Política Pública, Vol. XVI, № 2.

CLAD (2000). La responsabilización en la Nueva Gestión Pública Latinoamericana. CLADBID-EUDEBA. Buenos Aires.

Depetris, Jorge (2011). "Deportes Extremos: Construyendo capacidades estatales en la lucha contra el narcotráico. El caso de la Aduana Argentina (2005-2010)", Cuadernos del Instituto AFIP, № 21, Buenos Aires.

Fayol, Henry (1971). Administración Industrial y General, Buenos Aires, El Ateneo.

Franco, Rolando (1996). "Los paradigmas de la política social en América Latina", CEPAL, LC/R.1625, Santiago de Chile.

Guerra, Sérgio (2012). Agências Reguladoras, Belo Horizonte: Editora Fórum.

Gulick, Luther (1937[1999]). "Notas sobre la teoría de la organización», en Shafritz, Jay y Albert Hyde (comps.) Clásicos de la Administración Pública, México, Fondo de Cultura Económica.

ITF-UNSAM (2013). Informe Final del Foro de ferrocarriles metropolitanos. Una estrategia para la rehabilitación de los ferrocarriles metropolitanos de Buenos Aires, San Martín. 
Kaufmann, Franz-Xavier, Giandomenico Majone y Vicent Ostrom (eds.) (1985). Guidance, Control and Evaluation in the Public Sector, Berlin: Walter de Gruyter.

Kohon, Jorge (2019). "Transporte ferroviario» en Barbero, José y Julián Bertranou, op. cit.

Laegreid, Per, Paul Roness y Kristin Rubecksen (2008). "Controlling Regulatory Agencies", Scandinavian Political Studies, Vol. 31(1): 1-26.

Lazcano, Marcelo (2016). «El open Access en el transporte ferroviario en Alemania. Logros a mitad de camino", Documentos de Trabajo del Instituto del Transporte, № 4.

López, Beatriz y Roxana Rubins (2012). "La Administración Pública Nacional», en Abal Medina, Juan Manuel y Horacio Cao (comps.), Manual de la Nueva Administración Pública Argentina, Buenos Aires: Ariel.

Majone, Giandomenico y Antonio La Spina (1993). "El Estado regulador», Gestión y Política Pública, 11(2).

Martínez Nogueira, Roberto (2002). "Las administraciones públicas paralelas y las capacidades institucionales: la gestión por proyectos y las unidades ejecutoras", en Reforma y Democracia, No. 24, Caracas.

Mayntz, Renate y T.P. Hughes (eds) (1988). The Development of Large Technical Systems, Frankfurt, Campus.

Müller, Alberto (2018). La cuestión ferroviaria en la Argentina, Buenos Aires, Editorial Biblos.

Murillo, Victoria (2009). Political Competition, Partisanship and Policy Making in Latin American Public Utilities, Cambridge: Cambridge University Press.

Nahón, Carolina y Nicolas Bonfiglio (2007). «¿Entes de regulación o control? Imprecisiones del "moderno" esquema de regulación: reflexiones y enseñanzas del caso argentino", RAP 41(6): 1095-1120.

Nigrin, T. (2014). Open competition or discrimination on tracks? Examples of anti-competitive behavior of the Deutsche Bahn. Review of Economic Perspectives (Prague) 14, 16-33.

O’Donnell, Guillermo (1996). Otra institucionalización. En La Política. Revista de estudios sobre el Estado y la Sociedad № 2. Segundo Semestre. Buenos Aires. Paidós.

(1998). Accountability Horizontal. En Agora. Cuaderno de Estudios Políticos № 8. Año 4. Verano de 1998. Buenos Aires.

Olsen, Johan (2008). "The Ups and Downs of Bureaucratic Organization», Annual Review of Political Science, 11: 13-37.

Osborne, D. y Gaebler, T. (1994). La Reinvención del Gobierno, Barcelona: Paidós. 
Oszlak, Oscar (2003). «¿Responsabilizacion o respondibilidad?: el sujeto y el objeto de un Estado responsable", ponencia presentada en el VIII Congreso Internacional del CLAD, Panamá.

Oszlak, Oscar, Ruth Felder y Karina Forcinito (2000). La capacidad regulatoria del Estado en Argentina, documento elaborado por la Maestría en Administración Pública, UBA.

Oszlak, Oscar (coord.) y otros (2001). Estudio de los organismos descentralizados del Poder Ejecutivo Nacional. Informe Final, Jefatura de Gabinete de Ministros, Buenos Aires.

Papazian, Arturo (2000). «Algunas reflexiones sobre el diseño institucional de los organismos de Regulación y Control del Transporte», Sindicatura, № 11, junio.

Pérez, Verónica (2012). "Conformación de un ámbito privilegiado de acumulación en el transporte ferroviario de pasajeros del área metropolitana de Buenos Aires (1990-2008)", Realidad Económica, 268, p. 128-149.

(2015). "Las vías de la transición. Transformaciones emergentes en el modelo de prestación de los servicios ferroviarios de pasajeros del área metropolitana de Buenos Aires (1990-2010)", Documentos de Trabajo del IT N² 2, UNSAM.

Pérez, Verónica y Julián Rebón (coord.) (2017). La perturbación como motor de la historia. Los ferrocarriles metropolitanos durante el kirchnerismo, Buenos Aires, Ed. Biblos.

Peters, B. Guy (2011). "The politics and management of agencies", Transylvanian Review of Administrative Sciences, Volumen Especial, pp 7-14.

Pollitt, Christopher y Geert Bouckaert (2004). Public Management Reform. A comparative Analysis, Oxford, Oxford University Press.

Rocca, Mariela (2013). "Continuidades y rupturas en el accionar del Estado argentino respecto de los servicios públicos (1976-2010)", Revista Enfoques, Vol. XI (18), p. 19-53

Serafinoff, Valeria (2011). Concesión y Regulación de Redes Viales en Argentina. La implementación de dos modelos regulatorios en el marco de perspectivas enfrentadas sobre el rol del Estado, Tesis de Doctorado, Universidad Nacional de San Martín.

Simon, Herbert (1937[1997]). "Los proverbios de la Administración", en Shafritz, Jay y Albert Hyde (comps.) Clásicos de la Administración Pública, México, Fondo de Cultura Económica.

Van Thiel, Sandra (2006). "Styles of Reform: Differences in quango creation between policy sectors in the Netherlands", Journal of Public Policy, Vol. 26, № 2, pp. 115-139, Cambridge University Press.

Wirth, Wolfgang (1985). "Control in Public Administration: Plurality, Selectivity and Redundancy", en Kaufmann, Franz-Xavier, Giandomenico Majone y Vicent Ostrom, eds., op. cit. 
Yesilkagit, Kutsal y Jorgen Christensen (2009). «Institutional design and Formal Autonomy: Political versus Historical and Cultural Explanations", en Journal of Public Administration Research and Theory, Vol 20: pp. 53-74.

\section{DOCUMENTOS OFICIALES}

- CNRT, Informe Desempeño Red Ferroviaria 2018.

- PTN (Procuración del Tesoro de la Nación), Dictámenes.

Bertranou, J. (2020). «El control de empresas estatales en la encrucijada. La Comisión Nacional de Regulación del Transporte y las nuevas sociedades ferroviarias en Argentina", DAAPGE, año 20, № 34 (ene-jun), 2020, pp. 7-43. Santa Fe, Argentina: UNL. 